\title{
Implicitly positive about alcohol? Implicit positive associations predict drinking behavior
}

Citation for published version (APA):

Houben, K. M. P. I., \& Wiers, R. W. H. J. (2008). Implicitly positive about alcohol? Implicit positive associations predict drinking behavior. Addictive Behaviors, 33(8), 979-986.

https://doi.org/10.1016/j.addbeh.2008.03.002

Document status and date:

Published: 01/01/2008

DOI:

10.1016/j.addbeh.2008.03.002

Document Version:

Publisher's PDF, also known as Version of record

Document license:

Taverne

Please check the document version of this publication:

- A submitted manuscript is the version of the article upon submission and before peer-review. There can be important differences between the submitted version and the official published version of record.

People interested in the research are advised to contact the author for the final version of the publication, or visit the DOI to the publisher's website.

- The final author version and the galley proof are versions of the publication after peer review.

- The final published version features the final layout of the paper including the volume, issue and page numbers.

Link to publication

\footnotetext{
General rights rights.

- You may freely distribute the URL identifying the publication in the public portal. please follow below link for the End User Agreement:

www.umlib.nl/taverne-license

Take down policy

If you believe that this document breaches copyright please contact us at:

repository@maastrichtuniversity.nl

providing details and we will investigate your claim.
}

Copyright and moral rights for the publications made accessible in the public portal are retained by the authors and/or other copyright owners and it is a condition of accessing publications that users recognise and abide by the legal requirements associated with these

- Users may download and print one copy of any publication from the public portal for the purpose of private study or research.

- You may not further distribute the material or use it for any profit-making activity or commercial gain

If the publication is distributed under the terms of Article $25 \mathrm{fa}$ of the Dutch Copyright Act, indicated by the "Taverne" license above, 


\title{
Implicitly positive about alcohol? Implicit positive associations predict drinking behavior
}

\author{
Katrijn Houben $^{\mathrm{a}, *}$, Reinout W. Wiers ${ }^{\mathrm{a}, \mathrm{b}, \mathrm{c}}$ \\ a Faculty of Psychology, Clinical Psychological Science, Maastricht University, Maastricht, The Netherlands \\ b Behavioral Science Institute, Radboud Universiteit, Nijmegen, The Netherlands \\ c IVO Addiction Research Institute Rotterdam, The Netherlands
}

\section{A R T I C L E I N F O}

\section{Keywords:}

Alcohol

Implicit cognition

Implicit Association Test

\begin{abstract}
A B S T R A C T
Research using unipolar Implicit Association Tests (IATs) demonstrated that positive but not negative implicit alcohol associations are related to drinking behavior. However, the relative nature of the IAT with respect to target concepts (i.e., alcohol vs. soft drinks) obscures the interpretation of IAT scores and their relationship to behavior. Here, results with unipolar alcohol vs. soft drinks IATs were compared to results with unipolar Single Target IATs (ST-IAT) for alcohol alone. As expected, positive implicit alcohol associations assessed with both the alcohol-soft drinks IAT and the alcohol ST-IAT were related to alcohol use. In contrast, negative implicit associations with alcohol, whether they were assessed with alcohol-soft drinks IAT or the alcohol ST-IAT, showed no relationship with drinking behavior. Importantly, the alcoholsoft drinks IAT also predicted alcohol use above the variance explained by explicit alcoholrelated cognitions, demonstrating that positive implicit associations with alcohol predict unique variance in drinking behavior.
\end{abstract}

(c) 2008 Elsevier Ltd. All rights reserved.

\section{Introduction}

Recent research suggests that indirect measures can be used to register implicit cognitions that are activated automatically and which can influence behavior outside conscious awareness (e.g., Gawronski, Hofmann, \& Wilbur, 2006). Indirect measures can thus provide unique insights in cognitive processes involved in addictive behaviors such as alcohol use and abuse which are likely to develop automaticity with increased substance use (e.g., Evans \& Coventry, 2006). Many studies that have addressed the role of implicit cognitions involved in alcohol use and abuse have done so using varieties of the Implicit Association Test (IAT; Greenwald, McGhee, \& Schwartz, 1998). The reason that the IAT is the most commonly used indirect measure is that it is easy to administer, produces large and robust effects and has been shown to provide a reliable and valid measure of implicit cognitions (e.g., Hofmann, Gawronski, Gschwendner, Le, \& Schmitt, 2005; Nosek, Greenwald, \& Banaji, 2006; Poehlman, Uhlmann, Greenwald, \& Banaji, 2005). The underlying logic of the IAT is that it should be easier to classify stimuli into two target concepts (e.g., flowers and insects) and two attribute categories (e.g., positive and negative) when associated concepts are assigned to the same response (e.g., flowers + positive and insects + negative) than when associated concepts are assigned to different responses (e.g., flowers + negative and insects + positive).

Evidence from the first studies that examined implicit alcohol-related cognitions using the IAT suggested that implicit evaluative associations with alcohol, or implicit attitudes, do not play an important role in drinking behavior. More specifically, Wiers, van Woerden, Smulders, and de Jong (2002) demonstrated that both light and heavy drinkers more easily paired alcohol with a negative evaluative category and soft drinks with a positive evaluative category than vice versa. Differentiation between light and heavy drinkers, however, was established with a second IAT that assessed implicit associations between alcohol and arousal: Heavy drinkers

\footnotetext{
* Corresponding author. Clinical Psychological Science, Maastricht University, PO BOX 616, 6200 MD Maastricht, The Netherlands. E-mail address: K.Houben@psychology.unimaas.nl (K. Houben).
} 
were faster when alcohol shared a response with arousal and soft drinks with sedation than in the reversed combination. Importantly, light drinkers did not show this IAT effect. Moreover, these findings were replicated both in a sample of heavy drinkers (Wiers, van de Luitgaarden, van den Wildenberg, \& Smulders, 2005) as well as in a sample of patients undergoing treatment (De Houwer, Crombez, Koster, \& De Beul, 2004). Hence, these findings suggest that implicit attitudes toward alcohol are not an important determinant of drinking behavior, at least not as important as implicit associations between alcohol and arousal.

However, the conclusion that implicit attitudes toward alcohol are not involved in drinking behavior may be premature. Importantly, the finding that people generally hold negative implicit attitudes toward alcohol regardless of their level of alcohol use could be due to the standard IAT procedure. Specifically, the IAT measures the strength of two target concepts, for example alcohol and soft drinks, with two evaluative categories, positive and negative. The implication of this so-called double bipolarity of the IAT is twofold. First, due to the bipolarity of the attribute dimension, IAT effects only indicate whether the target concepts are associated more strongly with one attribute category (e.g., negative) relative to the other attribute category (e.g., positive). Consequently, IAT effects are difficult to interpret and meaningful information may be lost when assessing implicit attitudes toward attitude objects for which ambivalence can be high, such as alcohol (e.g., Conner \& Sparks, 2002). For instance, it is theoretically possible that two participants show an IAT effect of the same size even though one participant only has negative implicit associations with alcohol while the other participant has both strong negative implicit associations with alcohol as well as somewhat weaker positive implicit associations with alcohol. Thus, given that implicit attitudes toward alcohol may be ambivalent, an IAT that presents the attribute dimension in a bipolar format is probably not be well-suited to assess all relevant implicit associations that may steer drinking behavior.

Second, because the target dimension in the IAT is also bipolar, the IAT procedure cannot reveal implicit attitudes toward single target concepts, but is instead limited to measuring the relative strengths of pairs of implicit attitudes. While this relative nature of the IAT is not a problem for most research questions, as many attitude concepts have a complementary category that can be used as a contrast in the IAT (e.g., black vs. white, old vs. young, self vs. other), it is a problem when one is interested in implicit attitudes toward a single target concept or when the target concept of interest does not have a natural complement. This bipolarity of the target dimension further complicates the interpretation of IAT effects. For instance, effects in an IAT that contrast alcohol with soft drinks can reflect both implicit attitudes toward alcohol and/or implicit attitudes toward soft drinks.

\subsection{Present study}

To further examine the role of implicit attitudes in drinking behavior, the present study assessed implicit attitudes toward alcohol with IAT variants that eliminated the bipolarity of the IAT procedure. Here, we used a variant of the IAT that presents the attribute dimension in a unipolar format (cf. Jajodia \& Earleywine, 2003). While a standard IAT contrasts two attribute categories with each other (e.g., positive vs. negative), unipolar IATs contrast the same attribute categories with neutral categories (e.g., positive vs. neutral and negative vs. neutral). In this way, a positive unipolar IAT can assess the strength of positive implicit associations with the target concepts and a negative unipolar IAT can measure the strength of negative implicit associations with the target concepts. Importantly, recent results with unipolar IAT variants already suggest a more important role of implicit attitudes in alcohol use and abuse compared to results with (standard) bipolar IATs: It was demonstrated that positive implicit associations with alcohol are at least moderately related to drinking behavior while negative implicit associations with alcohol are not (e.g., Houben \& Wiers, 2006a; Jajodia \& Earleywine, 2003; McCarthy \& Thompsen, 2006). Thus, these findings indicate that positive implicit alcohol associations, at least to some extent, steer drinking behavior whereas negative implicit alcohol associations do not influence behavior. Nevertheless, it should be noted that these unipolar IATs still present the target dimension in a bipolar format. Therefore, it cannot be ruled out that effects with negative unipolar IATs were unrelated to alcohol use because they reflected implicit associations with the contrast category, typically soft drinks, rather than implicit associations with alcohol.

To further resolve this issue, we also measured implicit attitudes toward alcohol with a non-relative variant of the IAT, the Single Target IAT (ST-IAT; Wigboldus, Holland, \& van Knippenberg, 2006; see also Karpinski \& Steinman, 2006). The ST-IAT is structurally similar to the IAT with the difference that only one target category is presented during the task. Thus, unlike the IAT, the ST-IAT measures implicit attitudes toward single target concepts, without the need of a contrast category. Further, we modified the ST-IAT so that it also presented the attribute dimension in a unipolar format similar to what was previously done successfully with the IAT. Hence, we used a positive unipolar ST-IAT to measure the strength of non-relative positive implicit associations with alcohol and a negative unipolar ST-IAT to measure the strength of non-relative negative implicit associations with alcohol. Further, we also measured implicit positive and negative associations with soft drinks using unipolar ST-IATs. Finally, we measured explicit alcohol-related and soft drink-related cognitions to examine how these explicit cognitions would relate to implicit alcohol-related and soft drink-related cognitions.

In sum, this study further examined the relationship between positive and negative implicit associations with alcohol and drinking behavior. First, it was expected that results with both the positive unipolar IAT and the positive unipolar alcohol ST-IAT would demonstrate a relationship between positive implicit alcohol associations and drinking behavior. Second, in line with previous findings, no relationship was expected between negative implicit alcohol associations assessed with the negative unipolar IAT and drinking behavior. In addition, if the negative unipolar alcohol ST-IAT also showed no relation between negative implicit alcohol associations and alcohol use, this would suggest that this finding was not due to contamination by implicit soft drink associations and would further support the conclusion that negative implicit associations with alcohol do not influence drinking behavior. 


\section{Method}

\subsection{Participants}

Participants were recruited through advertisements at Maastricht University. A total of 62 female students of Maastricht University participated in the study. At the end of the study, all participants received either course credit or $10 €$ in the form of a gift certificate for their cooperation.

\subsection{Materials and measures}

\subsubsection{Alcohol use}

Alcohol use was measured through a self-report questionnaire (Wiers, Hoogeveen, Sergeant \& Gunning, 1997) based on the timeline follow-back method (TLFB; Sobell \& Sobell, 1990). Participants were asked to indicate how many drinks of different types of alcoholic beverages they consumed during each day of the past week, and for each day of the week, how many drinks they typically consumed on this day of the week.

\subsubsection{Alcohol-related problems}

Alcohol-related problems were assessed with the 18-items version of the Rutgers Alcohol Problem Index (RAPI; White \& Labouvie, 2000) and with the Alcohol Use Disorder Identification Test (AUDIT; Saunders, Aasland, Babor, De la Fuente, \& Grant, 1993). The RAPI described 18 alcohol-related problems or situations for which participants indicated how often they experienced these situations on a 5 -point Likert scale $(0=$ never, $4=$ very often) (Cronbach's $\alpha=.86)$. The AUDIT consisted of 10 questions in a multiple choice format. The first three questions were related to alcohol use, the other seven to alcohol-related problems $(\alpha=.83)$.

\subsubsection{Implicit associations}

In total, participants performed 6 unipolar task variants: A positive and a negative unipolar IAT that contrasted the two target categories 'alcohol' and 'soft drinks', a positive and a negative unipolar ST-IAT with the single target category 'alcohol', and a positive and a negative unipolar ST-IAT with the single target category 'soft drinks'. The 'alcohol' target category consisted of 5 alcoholic drinks (label 'alcohol'), while the 'soft drinks' target category consisted of 5 soft drinks (label 'soft drinks'). The two (Dutch) target categories were matched on word length and number of syllables. In all positive unipolar task variants, the positive attribute category (label 'pleasant'), consisting of 5 positive words, was paired with a neutral attribute category. Further, in the negative unipolar task variants, the negative attribute category (label 'unpleasant'), which consisted of 5 negative words, was also paired with a neutral attribute category. Thus, there were two neutral attribute categories ('label' neutral), each consisting of 5 words that were evaluated as neutral, which were paired with the positive and negative attribute categories in balanced order ${ }^{1}$. All attribute categories were matched on word length and number of syllables. All stimuli are listed in the Appendix A.

All tasks were programmed in ERTS 3.18 (Beringer, 1996). The positive and negative unipolar IAT followed the standard IAT procedure (see Greenwald et al., 1998) with a slight modification: participants practiced the target discrimination only once because it remained constant across both unipolar IATs. The target discrimination block consisted of 20 trials during which all target stimuli were presented twice. After the target discrimination, participants completed the positive unipolar IAT and the negative unipolar IAT in balanced order, each consisting of 4 blocks. In both unipolar IAT variants, participants first practiced the attribute classification during which all attribute stimuli were presented twice. Next, they received the combination block during which both target and attribute stimuli were presented twice for a total of 40 trials. Participants then practiced the reversed attribute discrimination, followed by the reversed combination block. The alcohol and soft drink unipolar ST-IATs followed a similar procedure as the unipolar IATs with two exceptions (see also Wigboldus et al., 2006). First, there was no target discrimination block because only one target category was presented during the unipolar ST-IATs. Second, in the combination blocks, stimuli of the two categories that shared a response were presented twice, while stimuli of the unpaired category were presented four times in order to keep the number of right and left responses equal. An overview of all unipolar IAT and unipolar STIAT blocks is shown in Table 1.

The assignment of the alcohol category and the soft drink category to the response keys was balanced across participants and remained constant across all task versions. Further, the response assignment of the attribute categories was also counterbalanced so that half the participants in each task performed the compatible combination task (i.e., alcohol+ negative (positive) vs. soft drinks + neutral for the unipolar IATs, and alcohol/soft drinks + negative (positive) vs. neutral for the unipolar ST-IATs) before the incompatible combination task (i.e., alcohol+ neutral vs. soft drinks + negative (positive) for the unipolar IATs, and alcohol/soft drinks + neutral vs. negative (positive) for the unipolar ST-IATs). The other half of the participants always performed the incompatible combination task before the compatible combination task. During all task variants, target and attribute stimuli were presented in the middle of the computer screen, in black against a grey background. Instructions were presented before each task. During each task, the labels of the categories assigned to the left and right response key were presented in the corresponding upper corners of the computer screen. Stimuli remained on screen until a response was given. The intertrialinterval was 250 ms. Feedback

\footnotetext{
1 The two neutral categories that were paired with the positive and negative attribute categories were heterogeneous sets of neutral words for half the participants, and homogeneous sets of neutral words, which were all synonyms of the word 'neutral', for the other half of the participants. The composition (heterogeneous or homogeneous) of the neutral categories did not influence any of the results.
} 
Table 1

Overview of IAT and ST-IAT phases

\begin{tabular}{|c|c|c|c|c|c|c|c|c|c|}
\hline \multicolumn{5}{|l|}{ IAT } & \multicolumn{5}{|l|}{ ST-IAT } \\
\hline Block & Trials & Function & Left key & Right key & Block & Trials & Function & Left key & Right key \\
\hline 1 & 20 & Target practice & Alcohol & Soft drinks & & & & & \\
\hline 2 & 20 & Attribute practice & Pleasant & Neutral & 1 & 20 & Attribute practice & Pleasant & Neutral \\
\hline $3 a$ & 20 & $\begin{array}{l}\text { Compatible combination } \\
\text { practice }\end{array}$ & $\begin{array}{l}\text { Alcohol } \\
\text { Pleasant }\end{array}$ & $\begin{array}{l}\text { Soft drinks } \\
\text { Neutral }\end{array}$ & $2 a$ & 20 & $\begin{array}{l}\text { Compatible combination } \\
\text { practice }\end{array}$ & $\begin{array}{l}\text { Alcohol } \\
\text { Pleasant }\end{array}$ & Neutral \\
\hline $3 b$ & 20 & $\begin{array}{l}\text { Compatible combination } \\
\text { test }\end{array}$ & $\begin{array}{l}\text { Alcohol } \\
\text { Pleasant }\end{array}$ & $\begin{array}{l}\text { Soft drinks } \\
\text { Neutral }\end{array}$ & $2 b$ & 20 & $\begin{array}{l}\text { Compatible combination } \\
\text { test }\end{array}$ & $\begin{array}{l}\text { Alcohol } \\
\text { Pleasant }\end{array}$ & Neutral \\
\hline 4 & 20 & Reversed attribute practice & Neutral & Pleasant & 3 & 20 & Reversed attribute practice & Neutral & Pleasant \\
\hline $5 a$ & 20 & $\begin{array}{l}\text { Incompatible combination } \\
\text { practice }\end{array}$ & $\begin{array}{l}\text { Alcohol } \\
\text { Neutral }\end{array}$ & $\begin{array}{l}\text { Soft drinks } \\
\text { Pleasant }\end{array}$ & $4 a$ & 20 & $\begin{array}{l}\text { Incompatible combination } \\
\text { practice }\end{array}$ & $\begin{array}{l}\text { Alcohol } \\
\text { Neutral }\end{array}$ & Pleasant \\
\hline $5 b$ & 20 & $\begin{array}{l}\text { Incompatible combination } \\
\text { test }\end{array}$ & $\begin{array}{l}\text { Alcohol } \\
\text { Neutral }\end{array}$ & $\begin{array}{l}\text { Soft drinks } \\
\text { Pleasant }\end{array}$ & $4 b$ & 20 & $\begin{array}{l}\text { Incompatible combination } \\
\text { test }\end{array}$ & $\begin{array}{l}\text { Alcohol } \\
\text { Neutral }\end{array}$ & Pleasant \\
\hline
\end{tabular}

Blocks are shown for the positive unipolar IAT and the positive unipolar alcohol ST-IAT. In the positive unipolar soft drink ST-IAT, the alcohol category was replaced by the soft drink category. Blocks 2 to 5 were repeated in the negative unipolar task variants with the attribute categories 'unpleasant' and 'neutral'.

was presented in red beneath the stimuli after an incorrect response ('wrong'), and when responses were too fast ( $<300$ ms; 'too fast') or too slow (>3000 ms; 'too slow').

\subsubsection{Explicit expectancies and attitudes}

Participants filled out two expectancy questionnaires, one relating to alcohol and the other to soft drinks, which consisted of 6 positive expectancy items ( $\alpha=.93, \alpha=.92$, respectively), and 6 negative expectancy items ( $\alpha=.81$, $\alpha=.92$, respectively). Each item asked participants to indicate on a Visual Analogue Scale (VAS) how much they agreed $(0=$ completely disagree, $100=$ completely agree) with the following statement: "After drinking alcohol (soft drinks), I feel ...". This statement was completed with the same words that were used for the positive and negative attribute categories of the unipolar IATs and ST-IATs, including the labels.

Attitudes toward alcohol and soft drinks were assessed with two attitude questionnaires which consisted of 5 positive $(\alpha=.86$, $\alpha=.89$, respectively) and 5 negative items ( $\alpha=.91, \alpha=.91$, respectively). In both questionnaires, participants indicated on a 100 mm VAS whether they agreed $(0=$ completely disagree, $100=$ completely agree) with the statement: "I think drinking alcohol (soft drinks) is ...", which was completed with the following words good, fun, smart, positive, and pleasant for the positive items and the words bad, stupid, boring, negative, and unpleasant for the negative items.

\subsection{Procedure}

After signing the informed consent form, participants performed the positive and negative unipolar IAT, the positive and negative unipolar alcohol ST-IAT, and the positive and negative unipolar soft drink ST-IAT. Half the participants performed the unipolar IATs before the unipolar alcohol and soft drink ST-IATs, while this task order was reversed for the other participants. Further, the order of the unipolar alcohol ST-IATs and the unipolar soft drink ST-IATs was also counterbalanced. Research suggests that the order in which the IAT and explicit measures are performed does not influence results (e.g., Nosek et al., 2006; Nosek, Greenwald, \& Banaji, 2005). However, because performing explicit measures before the IAT may change the context in which implicit associations are measured or perhaps even the underlying implicit associations themselves, participants in this study performed the IAT variants before filling out the questionnaires. After performing the IAT variants, participants filled out the expectancy and attitude questionnaires related to alcohol and soft drink in balanced order. Finally, participants filled out the questionnaires on alcohol use and alcohol-related problems.

\section{Results}

\subsection{Implicit associations}

Unipolar IAT and ST-IAT effects were calculated with the D600 scoring algorithm (Greenwald, Nosek, \& Banaji, 2003). For the positive and negative unipolar IATs, the D600 measure was calculated so that higher scores indicate faster performance when alcohol was paired with positive or negative attributes, respectively, and soft drinks with neutral attributes than in the reversed combination. With respect to the positive and negative unipolar alcohol and soft drink ST-IATs, higher D600 scores reflect faster performance when either of the target concepts was paired with positive attributes or negative attributes, respectively, and neutral attributes were assigned to the other response key than for the reversed combination. Further, following the formula presented by Greenwald et al. (2003), practice trials were always included, error penalties (600 ms) were given, and results were standardized at the level of the participant. 
Table 2

Correlations of implicit and explicit alcohol-related and soft drink-related cognitions and drinking behavior

\begin{tabular}{|c|c|c|c|c|c|c|c|c|c|c|c|}
\hline \multirow[t]{2}{*}{ Variable } & & \multicolumn{2}{|l|}{ IAT } & \multicolumn{2}{|c|}{ Alcohol ST-IAT } & \multicolumn{2}{|c|}{ Soft drink ST-IAT } & \multicolumn{2}{|c|}{ Explicit alcohol } & \multicolumn{2}{|c|}{ Explicit soft drink } \\
\hline & & Positive & Negative & Positive & Negative & Positive & Negative & Positive & Negative & Positive & Negative \\
\hline \multirow[t]{2}{*}{ IAT } & Positive & - & & & & & & & & & \\
\hline & Negative & .25 & - & & & & & & & & \\
\hline \multirow[t]{2}{*}{ Alcohol ST-IAT } & Positive & .19 & -.06 & - & & & & & & & \\
\hline & Negative & .15 & .13 & .15 & - & & & & & & \\
\hline \multirow[t]{2}{*}{ Soft drink ST-IAT } & Positive & .04 & -.10 & .03 & .11 & - & & & & & \\
\hline & Negative & -.04 & -.12 & .03 & -.17 & $.28 *$ & - & & & & \\
\hline \multirow[t]{2}{*}{ Explicit alcohol } & Positive & .19 & .11 & .16 & -.10 & -.10 & .09 & - & & & \\
\hline & Negative & -.11 & -.02 & -.01 & .04 & .03 & -.14 & $-.61 * *$ & - & & \\
\hline \multirow[t]{2}{*}{ Explicit soft drink } & Positive & -.02 & .12 & -.17 & -.06 & -.17 & -.12 & .10 & .13 & - & \\
\hline & Negative & .08 & -.01 & $.27 *$ & .09 & .12 & .09 & .04 & .15 & $-.56^{* *}$ & - \\
\hline Alcohol use & & $.44^{* *}$ & .07 & $.27 *$ & -.03 & .04 & .00 & $.46^{* *}$ & -.21 & -.13 & $.30^{*}$ \\
\hline
\end{tabular}

$*=$ Correlation is significant at the 0.05 level, $* *=$ Correlation is significant at the 0.01 level (2-tailed).

Preparatory analyses revealed no influential outliers on unipolar IAT and ST-IAT data. With respect to the positive and negative unipolar IAT, results showed that positive IAT effects were not significant, $t(61)=1.05, p=.298$, while negative IAT effects were significant, $t(61)=7.25, p<.001$. Hence, these findings demonstrate negative implicit alcohol associations but not positive implicit alcohol associations when implicit associations with alcohol were assessed relative to soft drinks. Similar to results with the negative unipolar IAT, a significant effect emerged in the negative unipolar alcohol ST-IAT, $t(61)=4.25, p<.001$. In addition, the positive unipolar alcohol ST-IAT also yielded a significant effect, $t(61)=3.44, p=.001$, revealing that participants also held positive implicit associations with alcohol. Finally, neither the positive or negative unipolar soft drink ST-IAT yielded a significant effect, $t$ $(61)=-1.49, p=.142$, and $t(61)=1.07, p=.287$, respectively. As can be seen in Table 2, unipolar IATs were uncorrelated with the unipolar alcohol and soft drink ST-IAT versions.

\subsection{Explicit expectancies and attitudes}

A mean score was calculated for positive items of the expectancy and attitude questionnaires with respect to alcohol $(\alpha=.93)$, as well as for positive items of the expectancy and attitude questionnaires with respect to soft drinks $(\alpha=.93)$. Similarly, we computed a mean score for negative expectancies and attitudes regarding alcohol $(\alpha=.87)$, and for negative soft drink-related expectancies and attitudes $(\alpha=.93)$. Results showed that participants were more negative toward alcohol $(M=34.64, \mathrm{SD}=18.56)$ than toward soft drinks $(M=23.24, \mathrm{SD}=17.26), t(61)=3.84, p<.001$, but equally positive toward alcohol $(M=55.65, \mathrm{SD}=15.53)$ as toward soft drinks $(M=51.44, S D=18.10), t(61)=4.21, p=.148$. None of the correlations between implicit and explicit cognitions reached significance except for an unexpected positive correlation between the positive unipolar alcohol ST-IAT and negative explicit soft drink-related cognitions (see Table 2).

\subsection{Prediction of drinking behavior}

Results on the TLFB showed that participants on average consumed $6.71(\mathrm{SD}=7.00)$ Dutch standard alcoholic drinks ${ }^{2}$ per week. On the RAPI, participants had an average item score of .26 $(\mathrm{SD}=.34)$, while participants' mean score on the AUDIT was 7.11 $(\mathrm{SD}=4.52)$. An estimate of drinking behavior was computed as the mean of average weekly alcohol use, alcohol use during the past week, and RAPI and AUDIT sum scores ${ }^{3}$. All variables were first z-transformed. Further, all variables were log-transformed in order to obtain a normal distribution for the dependent variable. As can be seen in Table 2, positive unipolar IAT scores as well as positive unipolar alcohol ST-IAT scores were significantly related to drinking behavior, demonstrating that stronger positive implicit associations with alcohol are associated with higher levels of alcohol consumption and alcohol-related problems. Negative implicit alcohol associations, in contrast, were unrelated to drinking behavior ${ }^{4}$. Further, the predictive validity of both the unipolar IATs and the unipolar alcohol ST-IATs was examined using hierarchical regression analysis. The regression analysis for the prediction of drinking behavior by unipolar IATs, unipolar alcohol ST-IATs, and explicit alcohol-related cognitions is shown in Table $3^{4,5}$. In step 1 , positive explicit alcohol-related cognitions significantly predicted drinking behavior. Further, the positive unipolar IAT entered in step 2 significantly increased the explained variance while the negative unipolar IAT was not a significant predictor of drinking

\footnotetext{
${ }^{2}$ A standard Dutch alcoholic drink contains somewhat less alcohol than a standard American alcoholic drink: $10 \mathrm{~g}$ vs. $14 \mathrm{~g}$.

${ }^{3}$ When average weekly alcohol use, alcohol use during the past week, RAPI scores, and AUDIT scores were entered in an exploratory factor analysis, only one factor with an Eigenvalue of $>1$ was extracted, which explained $68.77 \%$ of the variance. We therefore calculated a composite dependent variable from these four measures, which demonstrated good reliability (Cronbach's $\alpha=.85$ ).

${ }^{4}$ When alcohol consumption (i.e., average weekly alcohol consumption and alcohol consumption during the past week) and estimated alcohol-related problems (i.e., RAPI scores and AUDIT scores) were entered separately in the correlational analyses and the regression analyses, the pattern of results was similar to the result described for the composite drinking behavior variable.

${ }^{5}$ When the hierarchical regression analysis for the prediction of drinking behavior was performed separately for the unipolar IATs and for the unipolar alcohol ST-IATs, results were generally the same.
} 
Table 3

Summary of hierarchical regression analysis for the prediction of drinking behavior by explicit and implicit alcohol-related cognitions

\begin{tabular}{|c|c|c|c|c|c|c|c|}
\hline Step & Variable & B & SE B & $\beta$ & SE $\beta$ & $t$ & $p$ \\
\hline \multirow[t]{2}{*}{1} & Explicit positive alcohol cognitions & .03 & .01 & .53 & .15 & 3.66 & .001 \\
\hline & Explicit negative alcohol cognitions & .01 & .01 & .12 & .15 & .80 & .427 \\
\hline \multirow[t]{6}{*}{2} & Explicit positive alcohol cognitions & .02 & .01 & .43 & .14 & 3.02 & .004 \\
\hline & Explicit negative alcohol cognitions & .00 & .01 & .10 & .14 & .70 & .487 \\
\hline & Positive unipolar IAT & .65 & .20 & .37 & .12 & 3.20 & .002 \\
\hline & Negative unipolar IAT & -.08 & .18 & -.05 & .11 & -.43 & .670 \\
\hline & Positive unipolar alcohol ST-IAT & .22 & .18 & .13 & .11 & 1.19 & .240 \\
\hline & Negative unipolar alcohol ST-IAT & -.10 & .18 & -.06 & .11 & -.56 & .580 \\
\hline
\end{tabular}

Note. $F(2,59)=8.39, p=.001, R^{2}=.22$ for step $1 ; F_{\text {change }}(4,55)=3.53, p=.016, R_{\text {change }}^{2} .15$ for step 2 . Final model: $R^{2}=.37, R_{\text {adjusted }}^{2} .31, F(6,55)=5.48, p<.001$.

behavior. Also, neither the positive unipolar alcohol ST-IAT nor the negative unipolar alcohol ST-IAT significantly predicted drinking behavior.

\section{Discussion}

The present study examined the role of implicit and explicit attitudes in drinking behavior. Positive and negative implicit associations with alcohol were independently measured using unipolar IAT variants. As in previous studies, two unipolar IATs were used to assess positive and negative implicit alcohol associations relative to soft drinks (cf. Houben \& Wiers, 2006a; Jajodia \& Earleywine, 2003; McCarthy \& Thompsen, 2006). In addition, we also used two unipolar ST-IATs that measured positive and negative implicit associations with alcohol without a contrast category. The main focus of this study as to examine how these implicit alcohol-related associations would relate to drinking behavior and whether they would predict drinking behavior above explicit alcohol-related cognitions. Further, it was examined how scores on the unipolar IAT variants that assessed implicit alcohol associations would relate to unipolar ST-IATs that measured implicit associations with soft drinks as well as to explicit cognitions related to soft drinks.

With respect to the unipolar IATs, the present findings further supported the role of positive implicit associations with alcohol in drinking behavior. Although the positive unipolar IAT did not yield a significant effect, scores on the positive unipolar IAT did predict drinking behavior beyond the variance explained by explicit alcohol-related cognitions. In contrast, the negative unipolar IAT did yield a significant IAT effect, indicating that participants held negative implicit associations with alcohol, but these negative implicit alcohol associations were unrelated to drinking behavior. Hence, the present findings indicate that positive implicit associations with alcohol might play an important role in drinking behavior while drinking behavior is uninfluenced by the strength of negative implicit associations with alcohol, which is in line with previous studies (e.g., Houben \& Wiers, 2006a; Jajodia \& Earleywine, 2003; McCarthy \& Thompsen, 2006; see also de Jong, Wiers, van de Braak, \& Huijding, 2007). Possibly, negative implicit associations with alcohol reflect extrapersonal normative information with respect to drinking alcohol, shaped by culturally shared knowledge that does not influence drinking behavior. Support for this claim was recently found by Houben and Wiers (2007a, b) who demonstrated stronger positive than negative implicit associations with alcohol in a personalized IAT that was designed to reduce extrapersonal contamination (Han, Olson, \& Fazio, 2006; Olson \& Fazio, 2004).

Nevertheless, because the unipolar IAT, like the standard IAT, is a relative measure, present results with the positive and negative unipolar IATs as outlined above could (partially) reflect implicit associations with soft drinks in addition to implicit alcohol associations. Therefore, we also measured implicit alcohol associations with unipolar ST-IATs that do not require a contrast category. Both the negative and positive unipolar alcohol ST-IAT showed significant effects, demonstrating both positive and negative implicit associations with alcohol. Importantly, and in line with present results with the unipolar IATs, only scores on the positive unipolar alcohol ST-IAT were related to drinking behavior. Scores on the negative unipolar ST-IAT, however, showed no relationship to drinking behavior. Hence, findings with non-relative unipolar ST-IATs showed a similar pattern of results as findings with unipolar IATs, suggesting a role of positive implicit alcohol associations but not of negative implicit alcohol associations in drinking behavior. However, it is important to note that the positive unipolar ST-IAT, unlike the positive unipolar IAT, did not show incremental validity with respect to the prediction of drinking behavior.

The lack of incremental validity of the unipolar ST-IAT suggests superior validity of the unipolar IAT even though the latter is a non-relative measure. Further support for the validity of the unipolar IAT was demonstrated by the lack of correlations between the unipolar IATs and unipolar soft drink ST-IATs as well as explicit soft drink-related cognitions. It is also important to note that we did not find significant correlations between the positive unipolar IAT and the positive unipolar alcohol ST-IAT nor between the positive unipolar IAT and explicit alcohol-related cognitions. However, when these correlations were tested one-tailed, these correlations were borderline significant, suggesting a trend. Hence, the present findings suggest that the unipolar IAT is a valid measure of implicit alcohol associations that are moderately related to explicit alcohol-related cognitions and predictive of drinking behavior, while unrelated to implicit or explicit soft drink-related cognitions. These findings, thus, indicate that relativity of the unipolar IAT probably does not pose a threat to its validity as predictor of drinking behavior. Findings with the positive unipolar ST-IAT, on the other hand, were less compelling. 
There are several possible reasons for these differences in results with the unipolar IAT and the unipolar ST-IAT. First, it is possible that the relative unipolar IAT is a more valid measure of implicit alcohol associations because in real life, often a choice has to be made between drinking alcohol or non-alcoholic drinks. Thus, due to drinking experiences, implicit associations in memory might also be relative in nature and, therefore, they might be better captured using a relative indirect measure. Second, these differences in results may be due to lower validity of the unipolar ST-IAT. Since the unipolar ST-IAT presents only one target category in combination with a unipolar attribute dimension, the unipolar ST-IAT is probably much easier to perform than the unipolar IAT, which present two target categories in combination with the attribute dimension. Importantly, due its simplicity, the unipolar ST-IAT may measure other cognitive processes than implicit associations. For example, participants can easily classify items based on features such as saliency rather than category membership, since neutral items are less salient than for example alcohol-related stimuli and positive or negative stimuli (cf. recoding, see also De Houwer, Geldof, \& De Bruycker, 2005; Houben \& Wiers, 2006b; Mierke \& Klauer, 2001, 2003; Rothermund \& Wentura, 2004). Future research should, therefore, further examine whether presenting the attribute dimension in a unipolar format in combination with presenting only one target category deflates the validity of the unipolar ST-IAT in comparison to the unipolar IAT.

A limitation to the present findings is that the study used a cross-sectional design. Therefore, no conclusions about causality can be made based on these results. However, other recent studies have demonstrated that implicit alcohol-related associations prospectively predict drinking behavior after one year (Thush \& Wiers, 2007). Thus, together with the present findings, these results suggest an important role for implicit alcohol-related associations as determinants of drinking behavior. Further, the present study included only female participants due to pragmatic reasons (i.e., large female student population studying psychology at Maastricht University). However, similar conclusions regarding the role of implicit alcohol-related associations have also been demonstrated in male participants (e.g., Thush \& Wiers, 2007; Wiers et al., 2002). Finally, it should be noted that several other indirect measures have been developed that can assess implicit attitudes toward single attitude concepts besides the ST-IAT, including the Extrinsic Affective Simon Task (EAST; De Houwer, 2003) and the Go/No-Go Association Task (GNAT; Nosek \& Banaji, 2001). However, these measures are also unsuited to test positive and negative implicit associations separately. While no research has yet attempted to present the GNAT in a unipolar format, the EAST has been modified for this purpose, however, at the expense of losing its non-relative nature with respect to the target categories (Wiers, Ganushchack, Van de Ende, Smulders, \& de Jong, 2003). For now, it remains unclear whether these indirect measures can be modified so they are not only non-relative with respect to the targets, but also unipolar with respect to the attributes.

In conclusion, the present findings further support the role of positive implicit alcohol associations in drinking behavior. The implication of these findings is that intervention strategies aimed at reducing drinking should not only target explicit alcoholrelated cognitions but also positive implicit associations with alcohol. Hence, future research should examine ways to change the strength of implicit alcohol associations as well as their impact on drinking behavior.

\section{Appendix A. Target stimuli}

Alcohol: beer, wine, whisky, drink, vodka.

Soft drinks: Fanta, Coca Cola, Sprite, sinas (lemonade), ice-tea.

\section{Attribute stimuli}

Pleasant: amusing, sociable, happy, enjoyable, agreeable.

Unpleasant: down, lonely, unhappy, miserable, sad.

Neutral homogenous 1: standard, normal, general, common, objective.

Neutral homogenous 2: level, average, everyday, middle, universal.

Neutral heterogeneous 1: steep, compact, curved, regular, literally.

Neutral heterogeneous 2: brown, normal, digital, historically, general.

\section{References}

Beringer, J. (1996). Experimental Run Time System (ERTS), Version 3.18. Frankfurt, Germany: BeriSoft.

Conner, M., \& Sparks, P. (2002). Ambivalence and attitudes. European Review of Social Psychology, 12, 37-70.

De Houwer, J. (2003). The Extrinsic Affective Simon Task. Experimental Psychology, 50, 77-85.

De Houwer, J., Crombez, G., Koster, E. H. W., \& De Beul, N. (2004). Implicit alcohol-related cognitions in a clinical sample of heavy drinkers. Journal of Behavior Therapy and Experimental Psychiatry, 35, 275-286.

De Houwer, J., Geldof, T., \& De Bruyker, E. (2005). The Implicit Association Test as a general measure of similarity. Canadian Journal of Experimental Psychology, 59, 228-239.

de Jong, P. J., Wiers, R. W., van de Braak, M., \& Huijding, J. (2007). Using the Extrinsic Affective Simon Test as a measure of implicit attitudes toward alcohol: Relationship with drinking behavior and alcohol problems. Addictive Behaviors, 32, 881-887.

Evans, J. S. B. T., \& Coventry, K. (2006). A dual process approach to behavioural addiction: The case of gambling. In R. W. Wiers \& A. W. Stacy (Eds.), Handbook of Implicit Cognition and Addiction (pp. 29-43). Thousand Oaks, CA: SAGE Publishers.

Gawronski, B., Hofmann, W., \& Wilbur, C. J. (2006). Are "implicit" attitudes unconscious? Consciousness and Cognition, 15, 485-499.

Greenwald, A. G., McGhee, D. E., \& Schwartz, J. L. K. (1998). Measuring individual differences in implicit cognition: The Implicit Association Test. Journal of Personality and Social Psychology, 74, 1464-1480.

Greenwald, A. G., Nosek, B. A., \& Banaji, M. R. (2003). Understanding and using the Implicit Association Test: I. An improved scoring algorithm. Journal of Personality and Social Psychology, 85, 197-216. 
Han, H. A., Olson, M. A., \& Fazio, R. H. (2006). The influence of experimentally-created extrapersonal associations on the Implicit Association Test. Journal of Experimental Social Psychology, 42, 259-272.

Hofmann, W., Gawronski, B., Gschwendner, T., Le, H., \& Schmitt, M. (2005). A meta-analysis on the correlation between the Implicit Association Test and explicit self-report measures. Personality and Social Psychology Bulletin, 31, 1369-1385.

Houben, K., \& Wiers, R. W. (2006). Assessing Implicit Alcohol Associations with the Implicit Association Test: Fact or Artifact? Addictive Behaviors, 31, $1346-1362$.

Houben, K., \& Wiers, R. W. (2006). A Test of the salience asymmetry interpretation of the Alcohol-IAT. Experimental Psychology, 53, $292-300$.

Houben, K., \& Wiers, R. W. (2007). Are drinkers implicitly positive about drinking alcohol? Personalizing the alcohol-IAT to reduce negative extrapersonal contamination. Alcohol and Alcoholism, 42, 301-307.

Houben, K., \& Wiers, R. W. (2007). Personalizing the alcohol-IAT with individualized stimuli: Relationship with drinking behavior and drinking-related problems. Addictive Behaviors, 32, 2852-2864.

Jajodia, A., \& Earleywine, M. (2003). Measuring alcohol expectancies with the Implicit Association Test. Psychology of Addictive Behaviors, 17, 126-133.

Karpinski, A., \& Steinman, R. B. (2006). The single-category Implicit Association Test as a measure of implicit social cognition. Journal of Personality and Social Psychology, 91, 16-32.

McCarthy, D. M., \& Thompsen, D. M. (2006). Implicit and explicit measures of alcohol and smoking cognitions. Psychology of Addictive Behaviors, 20, 436-444.

Mierke, J., \& Klauer, K. C. (2001). Implicit association measurement with the IAT: Evidence for effects of executive control processes. Zeitschrift für Experimentelle Psychologie, 48, 107-122.

Mierke, J., \& Klauer, K. C. (2003). Method-specific variance in the Implicit Association Test. Journal of Personality and Social Psychology, 85, $1180-1192$.

Nosek, B. A., \& Banaji, M. R. (2001). The go/no-go association task. Social Cognition, 19, 625-664.

Nosek, B. A., Greenwald, A. G., \& Banaji, M. R. (2005). Understanding and using the implicit association test: II. Method variables and construct validity. Personality and Social Psychology Bulletin, 31, 166-180.

Nosek, B. A., Greenwald, A. G., \& Banaji, M. R. (2006). The Implicit Association Test at age 7: A methodological and conceptual review. In J. A. Bargh (Ed.), Social psychology and the unconscious. The automaticity of higher mental processes (pp. 265-292). Psychology Press.

Olson, M. A., \& Fazio, R. H. (2004). Reducing the influence of extra-personal associations on the Implicit Association Test: Personalizing the IAT. Journal of Personality and Social Psychology, 86, 653-667.

Poehlman, T. A., Uhlmann, E., Greenwald, A. G., \& Banaji, M. R. (2005). Understanding and using the Implicit Association test: 3. Meta-analysis of predictive validity. Manuscript submitted for publication.

Rothermund, K., \& Wentura, D. (2004). Underlying processes in the Implicit Association Test (IAT): Dissociating salience from associations. Journal of Experimental Psychology: General, 133, 139-165.

Saunders, J. B., Aasland, O. G., Babor, T. F., De la Fuente, J. R., \& Grant, M. (1993). Development of the Alcohol use Disorders Identification Test (AUDIT): WHO collaborative project on early detection of persons with harmful alcohol consumption. Addiction, 88, 791-804.

Sobell, L. C., \& Sobell, M. B. (1990). Self-report issues in alcohol abuse: State of the art and future directions. Behavioral Assessment, 12, 77-90.

Thush, C., \& Wiers, R. W. (2007). Explicit and implicit alcohol-related cognitions and the prediction of future drinking in adolescents. Addictive Behaviors, 32, 1367-1383.

White, H. R., \& Labouvie, E. W. (2000). Longitudinal trends in problem drinking as measured by the Rutgers Alcohol Problem Index. Paper presented at the 23rd Annual Scientific Meeting of the Research Society on Alcoholism. Denver, CO.

Wiers, R. W., Ganushchack, A., Van de Ende, N., Smulders, F. T. Y., \& de Jong, P. J. (2003). Comparing implicit alcohol associations across different rt-measures: The Implicit Association Test (IAT) versus varieties of the Extrinsic Affective Simon Task (EAST). Paper presented at the 15th Annual Convention of the American Psychological Association (APS). Atlanta, GA. May 29-June 1, 2003.

Wiers, R. W., Hoogeveen, K. J., Sergeant, J. A., \& Gunning, W. B. (1997). High- and low-dose alcohol-related expectancies and the differential associations with drinking in male and female adolescents and young adults. Addiction, 92, 871-888.

Wiers, R. W., van de Luitgaarden, J., van den Wildenberg, E., \& Smulders, F. T. Y. (2005). Challenging implicit and explicit alcohol-related cognitions in young heavy drinkers. Addiction, 100, 806-819.

Wiers, R. W., van Woerden, N., Smulders, F. T. Y., \& de Jong, P. J. (2002). Implicit and explicit alcohol-related cognitions in heavy and light drinkers. Journal of Abnormal Psychology, 111, 648-658.

Wigboldus, D. H. J., Holland, R. W., \& van Knippenberg, A. (2006). Single target implicit associations. Manuscript submitted for publication. 